PORTIONS OF THIS REPORT ARE ILLEGIBLE. It has baen roproduced from tho bost avilabile copy to permit the breadest pessiblo avait ability.

\title{
Plasma Energy Deposition from the Nuclear Elastic Scattering of Tritons on Tritons
}

\author{
Joseph J. Devaney
}

\section{DISCLAIMER}

\begin{abstract}
This report was prepared as an account of work sponsored by an agency of the United States Government. Neither the United States Government nor any agency thereof, nor any of their employees, makes any warranty, express or implied, or assumes any legal liability or responsibility for the accuracy, completeness, or usefulness of any information, apparatus, product, or process disclosed, or represents that its use would not infringe privately owned rights. Reference herein to any specific commercial product, process, or service by trade name, trademark, manufacturer, or otherwise does not necessarily constitute or imply its endorsement, recommendation, or favoring by the United States Government or any agency thereof. The views and opinions of authors expressed herein do not necessarily state or reflect those of the United States Government or any agency thereof.
\end{abstract}




\title{
PLASYA ENERGY DEPOSITION FROM THE NUCLEAR ELASTIC SCATTERING OF TRITUNS ON TRITONS
}

\author{
by \\ Joseph J. Devaney
}

\begin{abstract}
The rate of energy loss in a triton plasma suffered by tritons from nuclear forces elastic scattering plus nuclear Coulomb interference is calculated up to $3.5-\mathrm{MeV}$ triton energy .
\end{abstract}

\section{INTRODUCTION}

In computing the energy deposition or loss by heavy charged particles in a plasma, one must consider the energy loss mechanisms of the particle (a) to electrons by Coulomb interaction, (b) to nuclei by Coulomb and hadronic elastic scattering plus their interference, (c) to nuclei by nuclear reactions, and (d) by nuclear Bremsstrahlung (small). Many plasma texts, for example, Ref. 1, provide formulas for the pure Coulombic processes. This paper gives the energy deposition from the nuclear elastic scattering plus the interference with the nuclear Coulomb scattering of tritons from a triton plasma. Together with the electronic and nuclear energy losses, one then has the complete energy loss save from nuclear reactions, nuclear Bremsstrahlung, and collective effects.

Note that the electronic and nuclear Coulomb losses are density and temperature dependent. However, the nuclear forces-nuclear Coulomb interference and the hadronic terms are not density dependent (until nuclear matter densities or higher), i.e., no cutoff is required. We approximate the theory by regarding the mean relative velocity of triton to triton to be the velocity of the incident triton. Consequently, our results are inaccurate for 
incident triton energies not large compared to the triton temperature. We give our results in a form convenient for correction of the pure coulombic energy losses.

Since the Coulomb scattering of the charged triton by both electrons and tritons is strongly peaked in the forward direction, a useful description is the energy loss per unit path length. However, hadronic scattering can be large at large angles (here isotropic in the center of mass up to 3.5 MeV) so that its contribution leads to a more erratic path. (Not more than $45^{\circ}$ per collision, however, for we follow the most energetic resultant and $\left.E_{\text {triton }} \gg k T.\right)$ Nonetheless, energy deposition or loss per path length was judged appropriate because such losses are then in the usual Coulombic loss format, are relatively easy to obtain, and are matter configuration independent. Monte Carlo type calculations might be considered for a next step in refinement.

Because we deal with identical particles, we are faced with a choice of which particle to follow subsequent to a collision. We choose to follow the most energetic resulting triton so that the maximum laboratory scattering angle per collision will be $45^{\circ}$. We thus give the average energy loss as a function of path length of the most energetic remainder (triton) of each collision.

\section{CALCULATIONS}

We use the theory of Devaney and stein ${ }^{2}$ for spin $1 / 2$ particles. For nuclear and total scattering cross sections, we use the R-matrix analysis of the six nucleon system by Hale. 3 He has analyzed the existing data to -2 MeV and extrapolated his theory to $3.5 \mathrm{MeV}$. He calculates an isotropic nuclear (hadronic) scattering at all energies in the center of mass system. As a consequence, use of the approximate formulae of Devaney and Stein is, in fact, precise. We write for the differential cross sections in the center-of-mass system:

$$
\frac{\mathrm{d} a}{\mathrm{~d} \theta}=\sigma^{\prime},
$$


0 is the cross section and $\theta$ is the center-of-mass scattering angle. Let $\mathbb{E}_{t}$ be the energy of the original triton, $N_{t}$ be the triton particle density, and $x$ be the path length of the most energetic triton, i.e., originally the incident triton. Let $s$ refer to the total nuclear scattering, c to the nuclear coulomb part, $\mathrm{N}$ to the hadronic part, and I to their interference. Then the total scattering cross section is composed of the other three:

$$
\sigma_{S}^{\prime}=\sigma_{C}^{\prime}+\sigma_{N}^{\prime}+\sigma_{I}^{\prime} .
$$

Devaney and Stein ${ }^{2}$ give for the mean energy loss from hadronic plus interference scattering ( $\operatorname{spin} 1 / 2$ or 0 ):

$$
\begin{aligned}
\left.\Psi \equiv \frac{10^{24}}{N_{t} E_{t}} \cdot \frac{\overline{d E_{t}}}{d x}\right|_{N I}= & \frac{\pi}{60}\left[60 d_{-} \ln 2+130_{N}^{\prime}\left(\theta=90^{\circ}\right)\right. \\
& \left.+16 \sigma_{N}^{\prime}\left(\theta=60^{\circ}\right)+\sigma_{N}^{\prime}(\theta=0)\right] \text { (barns), }
\end{aligned}
$$

defining $\Psi$, and for the total scattering cross section:

$$
\sigma_{s}^{\prime}=\sigma_{c}^{\prime}+\frac{d_{-}}{\left(1-\mu^{2}\right)}+d_{0}+d_{2} \mu^{2}+d_{4} \mu^{4},
$$

where $\mu \equiv \cos \theta$. To evaluate $d_{-}$in Eq. (3), we take $\theta=90^{\circ}$ or $\mu=0$ and find for Devaney and stein's ${ }^{2}$

$$
\sigma_{c}^{\prime}\left(\theta=90^{\circ}\right)=\frac{z_{2}^{4} e^{4}}{E_{t}^{2}}=\frac{e^{4}}{E_{t}^{2}} \text {, }
$$

where for tritons the charge number, $z_{2}=1$; e is the electron charge. We use the Devaney and stein estimate of the interference differential cross section: 


$$
a_{I}^{\prime}=\frac{d_{-}}{1-\mu}
$$

so that from Eqs. (4) and (2) at $\mu=0$

$$
d_{-}=\sigma_{s}^{\prime}\left(\theta=90^{\circ}\right)-\left(\frac{e^{4}}{E_{t}^{2}}\right)-o_{N}^{\prime}\left(\theta=90^{\circ}\right) .
$$

(The term $e^{4} / E_{t}^{2}$ must be multiplied by $10^{24}$ to give barns, i.e., it becomes $10^{24} \mathrm{e}^{4} / \mathrm{E}_{\mathrm{t}}^{2}, \mathrm{E}_{t}$ here in ergs.) Equation (7) substituted into Eq. (3) gives our result for the hadronic and Coulomb-hadronic part of the full energy-loss term. The total energy loss should include the electron and nuclear pure Coulomb terms (from another source ${ }^{1}$ ) plus collective effects, if any. We obtain $\sigma_{S}^{\prime}\left(\theta=90^{\circ}\right), \sigma_{N}^{\prime}\left(\theta=90^{\circ}\right)=\sigma_{N}^{\prime}\left(\theta=60^{\circ}\right)=\sigma_{N}^{\prime}(\theta=0)$ (since spherical symmetric up to $3.5 \mathrm{MeV}$ ) from the results of Hale 3 to give the values of Table I and Fig. 1. In Table I, we also give the actual energy loss from Eqs. (7) and (3) for a nominal mass density, $\rho=1 \mathrm{~g} / \mathrm{cm}^{3},\left[\mathrm{~N}_{\mathrm{t}}=1.9967(23)\right]^{4}$, by the following formula:

$$
\left.\frac{\overline{d E_{t}}}{d x}\right|_{N I}=\frac{N_{t} E_{t}}{10^{24}} \Psi
$$

The results of Table I and Fig. 1 are well over an order of magnitude greater than the estimates of Perkins and Cullen. 5 The difference may well be due to their use of $3 \mathrm{He}-3 \mathrm{He}$ cross sections as an estimate for the $\mathrm{T}-\mathrm{T}$ cross sections.

\section{ACKNOWLEDGMENTS}

It is a pleasure to acknowledge helpf'ul conversations with $R$. Arthur Forster and Gerald M. Hale. 
TABLE I

TRITON HADRONIC AND INTERFERENCE MEAN ENERGY LOSS INCIDENT ON TRITONS, GENERALLY AND AT $1 \mathrm{~g} / \mathrm{cm}^{3}$ DENSITY

\begin{tabular}{|c|c|c|c|c|c|}
\hline $\begin{array}{l}\text { Incident } \\
\text { Triton } \\
\text { Energy } \\
\text { (MeV) } \\
\end{array}$ & $\begin{array}{c}\Psi(\text { barns }) \equiv \\
\left(10^{\left.24 / N_{t} E_{t}\right)}\right. \\
\frac{d E_{t} / d x}{N I}\end{array}$ & 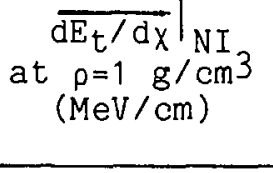 & $\begin{array}{l}\text { Incident } \\
\text { Triton } \\
\text { Energy } \\
\text { (MeV) } \\
\end{array}$ & $\begin{array}{c}\Psi(\text { barns }) \equiv \\
\left(10^{\left.24 / N_{t} E_{t}\right)}\right. \\
d E_{t} /\left.d x\right|_{N I}\end{array}$ & $\begin{array}{c}\left.\quad \overline{d E_{t} / d x}\right|_{N I} \\
\text { at } \rho_{T=1}=1 / \mathrm{cm} 3 \\
(M e V / c m)\end{array}$ \\
\hline $\begin{array}{l}0.01 \\
0.02\end{array}$ & $\begin{array}{r}-1 \cdot 35(-5) \\
3.3(-4)\end{array}$ & $\begin{array}{r}-27(-8) \\
1.31(-6)\end{array}$ & $\begin{array}{l}1.0 \\
1.2\end{array}$ & $\begin{array}{l}0.169 \\
0.152\end{array}$ & $\begin{array}{l}0.0336 \\
0.0365\end{array}$ \\
\hline $\begin{array}{l}0.04 \\
0.08 \\
0.1\end{array}$ & $\begin{array}{l}0.0128 \\
0.075 \\
0.104\end{array}$ & $\begin{array}{l}1.02(-4) \\
1.2(-3) \\
0.0021\end{array}$ & $\begin{array}{l}1.4 \\
1.6 \\
1.8\end{array}$ & $\begin{array}{l}0.137 \\
0.123 \\
0.111\end{array}$ & $\begin{array}{l}0.0382 \\
0.0392 \\
0.0398\end{array}$ \\
\hline $\begin{array}{l}0.12 \\
0.16 \\
0.2\end{array}$ & $\begin{array}{l}0.133 \\
0.171 \\
0.194\end{array}$ & $\begin{array}{l}0.0032 \\
0.0055 \\
0.0078\end{array}$ & $\begin{array}{l}2.0 \\
2.2 \\
2.4\end{array}$ & $\begin{array}{l}0.101 \\
0.094 \\
0.090\end{array}$ & $\begin{array}{l}0.0404 \\
0.0415 \\
0.0433\end{array}$ \\
\hline $\begin{array}{l}0.3 \\
0.4 \\
0.5\end{array}$ & $\begin{array}{l}0.217 \\
0.218 \\
0.212\end{array}$ & $\begin{array}{l}0.0130 \\
0.0174 \\
0.0211\end{array}$ & $\begin{array}{l}2.6 \\
2.8 \\
3.0\end{array}$ & $\begin{array}{l}0.088 \\
0.087 \\
0.087\end{array}$ & $\begin{array}{l}0.0459 \\
0.0489 \\
0.0520\end{array}$ \\
\hline $\begin{array}{l}0.6 \\
0.8\end{array}$ & $\begin{array}{l}0.204 \\
0.186\end{array}$ & $\begin{array}{l}0.0244 \\
0.0297\end{array}$ & 3.5 & 0.083 & 0.0583 \\
\hline
\end{tabular}




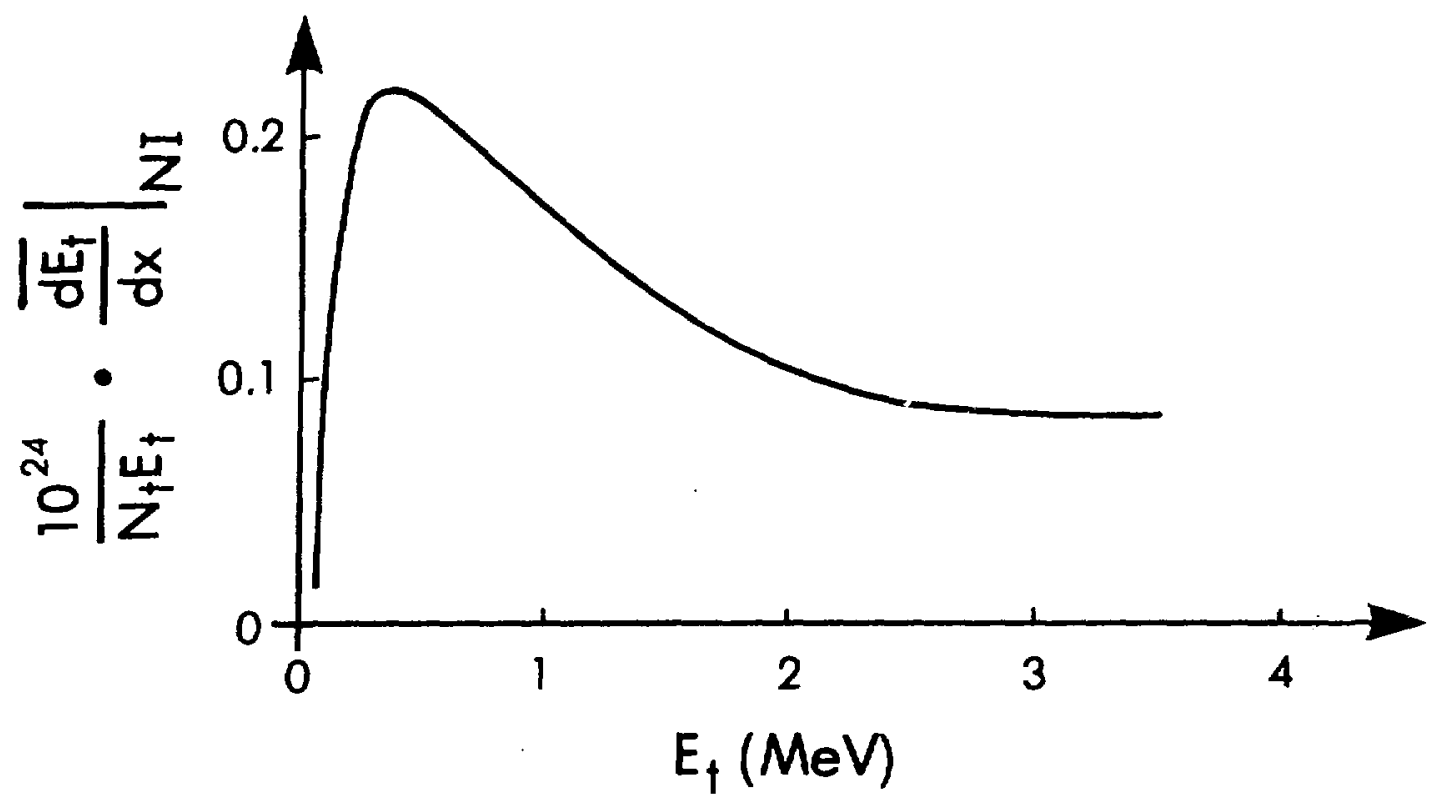

Fig. 1. Energy loss of $t$ from $T(t, t) T$

(includes Coulomb interference, but not Coulomb).

\section{REFERENCES}

1. C. L. Longmire, Elementary Plasma Physics (Interscience Publishers, New York, 1963).

2. J. J. Devaney and M. L. Stein, "Plasma Energy Deposition from Nuclear Elastic Scattering," Nucl. Sci. Eng. 46, 323 (1971).

3. G. Hale, "T-T Cross-Sections," to be published.

4. V. S. Shirley and C. M. Lederer, Eds., Nuclear Wallet Cards, Lawrence Berkeley Laboratory (January 1979).

5. S. T. Perkins and D. E. Cullen, "Elastic Nuclear PI us Interference Cross Sections for Light-Charged Particles," Nucl. Sci. Eng. 77, 20 (1981). 